\title{
Comparing bevacizumab and ranibizumab for initial reduction of central macular thickness in patients with retinal vein occlusions
}

This article was published in the following Dove Press journal:

Clinical Ophthalmology

5 July 2013

Number of times this article has been viewed

Michael A Singer'

Steven R Cohen ${ }^{2}$

Sylvia L Groth ${ }^{3}$

Salman Porbandarwalla ${ }^{2}$

'Medical Center Ophthalmology Associates (MCOA), San Antonio, Texas, USA; ${ }^{2}$ Department of Ophthalmology, University of Texas Health Science Center at San Antonio, San Antonio, Texas, USA; ${ }^{3}$ University of Minnesota Medical School, Minneapolis, Minnesota, USA
Correspondence: Michael Singer 9157 Huebner Road, San Antonio, TX 78240, USA

$\mathrm{Tel}+\mathrm{I} 20 \mathrm{I} 6972020$

Fax + I 2105587679

Email msinger@mcoayeycare.com
Purpose: To examine short-term effects of ranibizumab versus bevacizumab on reduction of optical coherence tomography (OCT) central macular thickness (CMT) in patients with macular edema secondary to retinal vein occlusions (RVOs).

Methods: This is a retrospective analysis in which patients with RVOs were injected with either bevacizumab or ranibizumab. At 2 weeks, all patients were injected with a dexamethasone intravitreal implant $\left(\right.$ Ozurdex $\left.^{\circledR}\right)$. CMT on OCT and best-corrected visual acuity were obtained at baseline, at 2 weeks (just prior to the dexamethasone intravitreal implant), and 6 weeks.

Results: Sixty-four patients received injections (32 bevacizumab; 32 ranibizumab). At 2 weeks, bevacizumab group had a mean ( \pm standard error of mean [SEM]) CMT reduction of $26.2 \% \pm 3.4 \%$ versus $47 \% \pm 3.5 \%$ reduction with ranibizumab $(P<0.0001)$. At 6 weeks, there was a $31.6 \% \pm 3.2 \%$ CMT reduction with bevacizumab versus $52 \% \pm 3.2 \%$ with ranibizumab $(P<0.0001)$. At 2 weeks, $15(9 \%)$ of bevacizumab patients versus $25(78.1 \%)$ ranibizumab patients achieved OCT CMT $<300 \mu \mathrm{m}(P=0.0192)$. At 6 weeks, $18(56.3 \%)$ of bevacizumab compared to $30(93.8 \%)$ of ranibizumab patients achieved CMT $<300 \mu \mathrm{m}(P=0.0010)$ Visual acuity was not significantly different at each time interval between the groups.

Conclusion: Ranibizumab appears to have a greater effect in the short-term of decreasing macular edema on OCT when compared to bevacizumab in patients with RVOs.

Keywords: anti-VEGF, central macular thickness, dexamethasone, intravitreal implant, macular edema, retinal vein occlusion

\section{Introduction}

Affecting an estimated 180,000 eyes per year in the United States, retinal vein occlusions (RVOs) are the second most common type of retinal vascular disorders. ${ }^{1,2}$ Branch RVOs (BRVOs) comprise approximately $80 \%$ of these, but both BRVOs and central retinal vein occlusions (CRVOs) contribute to significant vision loss, mostly as a result of macular edema. ${ }^{1-3}$ The Branch Vein Occlusion Study (BVOS) group helped to establish grid laser as the treatment standard for appropriate patients with macular edema, with this being the only proven beneficial treatment for many years. ${ }^{4}$ Following this, the Central Vein Occlusion Study (CVOS) group found that grid laser did in fact decrease macular edema, but did not demonstrate a statistically significant difference in visual acuity (VA) when compared to observation alone. ${ }^{5}$

In more recent years, studies have demonstrated significantly elevated levels of vascular endothelial growth factor (VEGF) in eyes with RVOs. ${ }^{6-8}$ These findings, along with the successful use of anti-VEGF medications for neovascular age related macular degeneration (ARMD), led to further studies investigating the use of anti-VEGF agents 
for the treatment of macular edema secondary to BRVO and CRVO. Ranibizumab (Lucentis ${ }^{\circledR}$, F. Hoffmann-La Roche Ltd, Basel, Switzerland) is a fragment, antigen binding (Fab) antibody that binds all forms of active VEGF-A, effectively reducing its actions on vascular endothelial cells. Both the BRAVO trial and the CRUISE trial demonstrated the effectiveness of intraocular injections of ranibizumab in improving best-corrected VA (BCVA) and central foveal thickness (CFT) in BRVOs and CRVOs, respectively. This led to US Food and Drug Administration (FDA)-approval for use of ranibizumab for treatment of macular edema following retinal vein occlusions. ${ }^{3,9}$

Bevacizumab (Avastin ${ }^{\circledR}$, F. Hoffmann-La Roche Ltd), a full length monoclonal antibody that also binds all forms of VEGF-A, has been used extensively off-label to treat macular edema secondary to BRVOs and CRVOs, as well as diabetic macular edema and neovascular ARMD. A recent review of several trials indicates that intravitreal bevacizumab improves VA and reduces CFT in macular edema associated with BRVOs. ${ }^{10}$ The Comparison of Age related Macular Degeneration Treatments Trials (CATT) has demonstrated equal effectiveness of bevacizumab versus ranibizumab for the treatment of neovascular ARMD in terms of VA. ${ }^{11}$ However, numerous studies have shown that VEGF levels are much higher in eyes with BRVOs, and highest in eyes with CRVOs when compared to eyes with ARMD, indicating a difference in the pathogenesis of the edema (Figure 1). This also explains why macular edema is more difficult to treat in CRVO patients. Despite their similar actions, bevacizumab and ranibizumab are different molecules, with different behaviors and properties. Case reports in the literature have shown that ranibizumab may have a stronger effect in resolving macular edema in RVOs when compared to bevacizumab. ${ }^{12}$ Given these differences it is necessary to investigate the use of these drugs in RVOs as a clinical entity separate from neovascular ARMD. The purpose of this study was to evaluate the very short-term effects of intravitreal bevacizumab (Avastin ${ }^{\circledR}$ ) versus ranibizumab (Lucentis $^{\circledR}$ ) on reducing central macular thickness (CMT) in patients with RVOs.

\section{Methods}

An institutional review board approved retrospective chart review was performed at a single center in which the charts of patients who underwent combination therapy using an anti-VEGF agent, bevacizumab or ranibizumab, and dexamethasone intravitreal implant (Ozurdex ${ }^{\circledR}$, Allergan Pharmaceuticals, Irvine, CA, USA) during the period of 2009-2012, were evaluated. The patients were part of a subset analysis of a combination trial in which patients diagnosed with RVOs received an intravitreal injection of $0.50 \mathrm{mg}$ (in $0.05 \mathrm{~mL}$ of solution) for ranibizumab, and $1.25 \mathrm{mg}$ (in $0.05 \mathrm{~mL}$ of saline) for bevacizumab at baseline, followed by a scheduled Ozurdex ${ }^{\circledR}$ implant 2 weeks later. ${ }^{13}$ Patients met inclusion criteria for analysis if this was their first RVO, or if the previous

\begin{tabular}{|c|c|c|}
\hline \multicolumn{2}{|r|}{ VEGF level } & Source \\
\hline \multirow{10}{*}{ 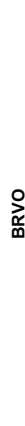 } & 226 & Noma, Graefes Arch Clin Exp Ophth, 2010 \\
\hline & 270 & Asato, ARVO, 2010 \\
\hline & 575 & Noma, Eur J Ophthalmol, 2008 \\
\hline & 613 & Shimura, Acta Ophthalmol, 2008 \\
\hline & 672 & Noma, Eye, 2008 \\
\hline & 809 & Fuller, ARVO, 2010 \\
\hline & 895 & Takahashi, IOVS, 2003 \\
\hline & 940 & Inomata, Neuro Report, 2004 \\
\hline & 1263 & Noma, Graefes Arch Clin Exp Ophth, 2006 \\
\hline & 2953 & Stahl, Retina, 2010 \\
\hline \multirow{5}{*}{ \} $&{435} &{\text { Noma, Ophthalmol, } 2009} \\
{\hline} &{435} &{\text { Noma, Eur J Ophthalmol, } 2010} \\
{\hline} &{744} &{\text { Asato, ARVO, } 2010} \\
{\hline} &{1689} &{\text { Fuller, ARVO, } 2010} \\
{\hline} &{ } &{9040^{*}} \\
{\hline \sum_{<}^{0}} &{39} &{\text { Holekamp, Am J Ophthalmol, } 2002} \\
{\hline \check{\jmath}_{3}^{\circ}} &{62} &{\text { Duh, Am J Ophthalmol, } 2004} \\
{\hline \text { ( }} &{2500} &{10,000} \\
$\hline}
\end{tabular}

Figure I Meta-analysis of VEGF levels among different diseases as determined by vitreous sampling.

Notes: *Noma, Eur J Ophthalmol, 2008. (Reproduced with permission). Singer MA, Bell DJ, Porbandarwalla S. Ischemia and VEGF in different retinal diseases and therapies: how does one influence the other? Retinal Physician. 2012;9:28-30. ${ }^{18} @$ Retinal Physician 2012.

Abbreviations: AMD, age related macular degeneration; BRVO, branch retinal vein occlusions; CRVOM, central retinal vein occlusion; VEGF, vascular endothelial growth factor. 
anti-VEGF therapy was at least 6 weeks prior, and CMT was greater than $300 \mu \mathrm{m}$ on spectral domain OCT (SD-OCT). Exclusion criteria included history of vitrectomy, rubeosis, or advanced glaucoma. The anti-VEGF agent injected was mostly determined by insurance coverage.

Patients were initially evaluated using best-corrected Snellen VA and SD-OCT (Zeiss Cirrus, Dublin, CA, USA) at baseline prior to injection of either bevacizumab or ranibizumab. Patients were then reevaluated 2 weeks after initial injection, at which time SD-OCT and VA were repeated. All patients received Ozurdex ${ }^{\circledR}$ at the 2-week visit as well. Six weeks after initial injection, a similar evaluation was repeated. The primary outcome measure was the resolution of initial edema as defined by CMT $<300 \mu \mathrm{m}$, at 2 weeks and 6 weeks after intravitreal injection of either ranibizumab or bevacizumab; and to examine if the addition of a second medication increases the number of patients who have resolution of their macular edema. Secondary outcomes included CMT reduction from baseline and VA. A two-tailed $t$-test was used to compare the outcome measures between the groups at baseline, 2 weeks, and 6 weeks (4 weeks after dexamethasone implant). A Fisher's exact test was used to compare the number of patients that achieved CMT $<300 \mu \mathrm{m}$. A repeated measures analysis of variance (ANOVA) was used to examine each group over the time intervals.

\section{Results}

Sixty-four patients were included in the study and followed from baseline to 6 weeks. Thirty-two patients received bevacizumab and 32 patients received ranibizumab. In the bevacizumab group, the mean age of the patient was 72 years \pm 2.5 years, with $69 \%$ female and $31 \%$ male. In the ranibizumab group, the mean age of the patient was 76 years \pm 2.1 years, also with $69 \%$ female and $31 \%$ male. Eleven patients had a CRVO and 21 had a BRVO in the bevacizumab group, versus 9 CRVOs and 23 BRVOs in the ranibizumab group (Table 1).

CMT at baseline in the bevacizumab group ranged from $309 \mu \mathrm{m}$ to $763 \mu \mathrm{m}$ with a mean of $450.8 \mu \mathrm{m} \pm$ (standard error of the mean [SEM]) $21.3 \mu \mathrm{m}$, and in the ranibizumab group $314 \mu \mathrm{m}$ to $988 \mu \mathrm{m}$ with a mean of $579.3 \mu \mathrm{m} \pm$ $35.6 \mu \mathrm{m}$. In terms of VA, the preinjection bevacizumab group ranged from $\log$ MAR of 0.1 to 1.8 with a mean of $0.71 \pm 0.07$ (Snellen 20/100-). The preinjection ranibizumab group ranged from $\log$ MAR of 0.2 to 2.3 with a mean of $0.89 \pm 0.1$ (Snellen 20/160+) (Table 2).

At 2 weeks postinjection, the mean CMT decreased to $327 \mu \mathrm{m} \pm 20.0 \mu \mathrm{m}$ in the bevacizumab group and $276 \mu \mathrm{m} \pm 9.2 \mu \mathrm{m}$ in the ranibizumab group (Figure 2). The mean percent change from baseline to 2 weeks was $-26.24 \% \pm 3.4 \%$ in the bevacizumab group and $-47 \% \pm 3.5 \%$ in the ranibizumab group $(P<0.0001)$. The mean 2 week $\log$ MAR for the bevacizumab group was $0.53 \pm 0.5(20 / 60-)$ compared with $0.58 \pm 0.1(20 / 80+)$ in the ranibizumab group $(P=0.6154$; Figure 3$)$.

At 6 weeks postinjection, the mean CMT for bevacizumab versus ranibizumab was $303.3 \mu \mathrm{m} \pm 18.7 \mu \mathrm{m}$ and $248.3 \mu \mathrm{m} \pm 8.3 \mu \mathrm{m}$, respectively. The mean percent change from baseline to 6 weeks was $-31.58 \% \pm 3.2 \%$ in the bevacizumab group and $-52.10 \% \pm 3.2 \%$ in the ranibizumab group $(P<0.0001)$. The mean 6 week logMAR for the bevacizumab group was $0.47 \pm 0.05(20 / 60+)$ compared with $0.49 \pm 0.07$ (20/60-) in the ranibizumab group ( $P=0.7767$; Figure 3$)$.

At 2 weeks, 15 patients (46.9\%) in the bevacizumab group achieved a CMT $<300 \mu$ m versus 25 patients $(78.1 \%)$ in the ranibizumab group $(P=0.0192)$. At 6 weeks, 18 patients $(56.3 \%)$ in the bevacizumab group achieved or maintained CMT $<300 \mu \mathrm{m}$ compared to 30 patients $(93.8 \%)$ in the ranibizumab group ( $P=0.0010)$ (Figures 4 and 5).

The bevacizumab and ranibizumab groups both had a statistically significant reduction in CMT (bevacizumab $P<0.0001$; ranibizumab $P<0.0001)$ and improvement in $\log$ MAR VA (bevacizumab $P<0.0001$; ranibizumab $P<0.0001)$ over each of the time intervals.

In patients who had BRVOs, at 2 weeks, there was a statistically significant difference in the amount of reduction of CMT with ranibizumab versus bevacizumab $(P=0.0070)$. In addition,

Table I Baseline characteristics of the two groups

\begin{tabular}{|c|c|c|c|c|c|}
\hline & $\begin{array}{l}\text { Number } \\
\text { of patients }\end{array}$ & $\begin{array}{l}\text { Mean age, } \\
\text { years ( } \pm \text { SEM) }\end{array}$ & $\%$ Female & $\%$ Male & $\begin{array}{l}\text { Pretreated with } \\
\text { bevacizumab }\end{array}$ \\
\hline Bevacizumab & 32 & $72 \pm 2.5$ & 69 & 31 & 14 \\
\hline BRVO & 21 & $73.5 \pm 3.0$ & 71 & 29 & 11 \\
\hline CRVO & 11 & $69.8 \pm 4.4$ & 64 & 26 & 3 \\
\hline Ranibizumab & 32 & $76 \pm 2.1$ & 69 & 31 & 0 \\
\hline BRVO & 23 & $77.7 \pm 2.2$ & 63 & 37 & 0 \\
\hline CRVO & 9 & $71.0 \pm 4.9$ & 88 & 12 & 0 \\
\hline
\end{tabular}

Abbreviations: BRVO, branch retinal vein occlusions; CRVO, central retinal vein occlusions; SEM, standard error of the mean. 
Table 2 OCT central macular thickness with breakdown of BRVO and CRVO interval

\begin{tabular}{|c|c|c|c|}
\hline & $\begin{array}{l}\text { Baseline } \\
\text { ( } \pm \text { SEM) }\end{array}$ & $\begin{array}{l}2 \text { weeks } \\
( \pm \text { SEM })\end{array}$ & $\begin{array}{l}6 \text { weeks } \\
\text { ( } \pm \text { SEM) }\end{array}$ \\
\hline \multicolumn{4}{|l|}{ Bevacizumab } \\
\hline Total mean CMT $(\mu \mathrm{m})$ & $450.8 \pm 21.3$ & $327 \pm 20.0$ & $303.3 \pm 18.7$ \\
\hline BRVO mean CMT $(\mu \mathrm{m})$ & $427.8 \pm 20.1$ & $323.1 \pm 21.3$ & $299 \pm 23.1$ \\
\hline CRVO mean CMT $(\mu \mathrm{m})$ & $494.8 \pm 47.5$ & $334.6 \pm 43.2$ & $311.5 \pm 33.0$ \\
\hline \% Change CMT & N/A & -26.24 & -31.58 \\
\hline $\begin{array}{l}\text { Percentage of patients } \\
\text { with } \mathrm{CMT}<300 \mu \mathrm{m}(\%)\end{array}$ & 0 & 46.9 & 56.3 \\
\hline Mean logMAR VA & $0.71 \pm 0.07$ & $0.53 \pm 0.05$ & $0.47 \pm 0.05$ \\
\hline \multicolumn{4}{|l|}{ Ranibizumab } \\
\hline Total mean CMT $(\mu \mathrm{m})$ & $579.3 \pm 35.6$ & $276 \pm 9.2$ & $248.3 \pm 8.3$ \\
\hline BRVO mean CMT $(\mu \mathrm{m})$ & $564.8 \pm 43.5$ & $277 \pm I I . I$ & $252.4 \pm 10.5$ \\
\hline CRVO mean CMT $(\mu \mathrm{m})$ & $622.9 \pm 58.9$ & $273.3 \pm 16.8$ & $236.1 \pm 10.3$ \\
\hline \% Change CMT & $\mathrm{N} / \mathrm{A}$ & -47 & -52.1 \\
\hline $\begin{array}{l}\text { Percentage of patients } \\
\text { with } \mathrm{CMT}<300 \mu \mathrm{m}(\%)\end{array}$ & 0 & 78.1 & 93.8 \\
\hline Mean logMAR VA & $0.89 \pm 0.1$ & $0.58 \pm 0.1$ & $0.49 \pm 0.07$ \\
\hline
\end{tabular}

Abbreviations: BRVO, branch retinal vein occlusions; CMT, central macular thickness; CRVO, central retinal vein occlusions; logMAR, logarithm of the minimal angle of resolution; N/A, not applicable (before treatment); OCT, optical coherence tomography; VA, visual acuity.

$9 / 21(43 \%)$ in the bevacizumab group versus $19 / 24(79 \%)$ in the ranibizumab group achieved a $\mathrm{CMT}<300 \mu \mathrm{m}(P=0.0161)$. At 6 weeks, there was also a significant difference in the reduction of CMT with ranibizumab versus bevacizumab $(P=0.006)$. In terms of OCT CMT $<300 \mu \mathrm{m}, 12 / 21$ (57\%) patients in the bevacizumab group achieved this goal compared to $22 / 24$ (92\%) in the ranibizumab group $(P=0.0132)$ (Figure 6).

When looking at CRVO patients, at 2 weeks there was a statistically significant difference in the mean percentage of reduction of macular edema with ranibizumab versus bevacizumab $(P=0.0025)$. In terms of the macula being "dry", 6 patients in each group (of 11 total bevacizumab and 8 total ranibizumab) had a CMT $<300 \mu \mathrm{m}$ at 2 weeks $(P=0.6332)$. At 6 weeks, there was a statistically significant difference in the mean percentage of reduction of macular edema with

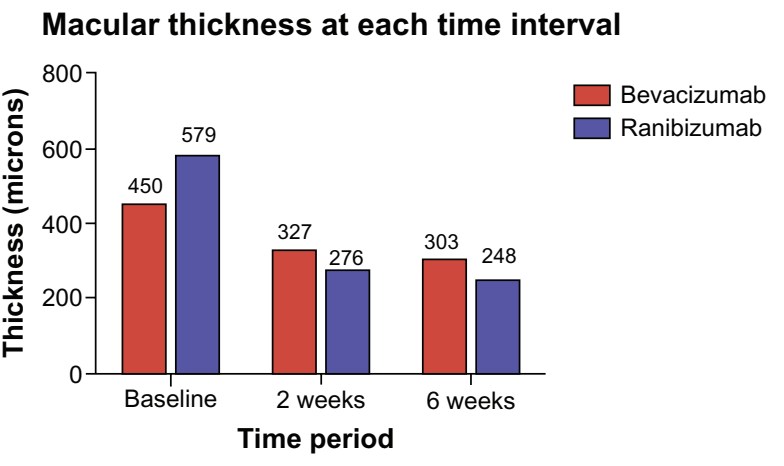

Figure 2 Mean CMT at baseline, 2 weeks, and 6 weeks. Abbreviation: CMT, central macular thickness.

\section{VA at each interval with bevacizumab and ranibizumab}

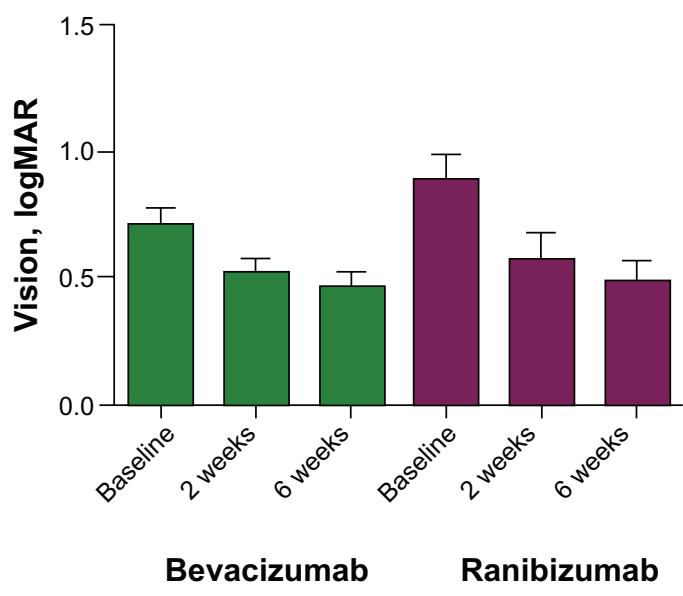

Figure 3 Mean logMAR at time intervals.

Note: No statistical difference between groups, but both groups had a statistically significant improvement from baseline.

Abbreviations: VA, visual acuity; logMAR, logarithm of minimal angle of resolution.

ranibizumab versus bevacizumab $(P=0.0081)$. The number of patients in the bevacizumab group $<300 \mu \mathrm{m}$ remained the same (6), while all of the patients (8) in the ranibizumab group were $<300 \mu \mathrm{m}(P=0.0445)$ (Figure 7$)$. There was no statistically significant difference in the logMAR VA between the bevacizumab and ranibizumab groups with subgroup analysis of BRVO versus CRVO patients.

Fourteen of the 32 patients in the bevacizumab group had received previous injection with bevacizumab greater than 6 weeks prior. Of these 14 patients, seven achieved a $\mathrm{CMT}<300 \mu \mathrm{m}$ at 2 weeks (Table 3 ).

\section{Discussion}

In this study comparing the short-term effects of bevacizumab versus ranibizumab for macular edema in patients with RVOs, ranibizumab appears to be more effective in terms of reducing CMT. The CATT 2-year results demonstrated that bevacizumab and ranibizumab are essentially equal for treatment of neovascular ARMD.${ }^{11}$ However, the VEGF levels found in the vitreous in BRVOs and especially CRVOs are significantly higher than in ARMD (Figure 1). Given these differences, the CATT data cannot be generalized to the macular edema in RVOs. Because of the higher VEGF levels, ranibizumab's higher affinity for the VEGF molecule may help to explain why it proves to be more effective in reducing CMT in this study. ${ }^{14}$ In addition, our study only looks at very short-term data (2 weeks and 6 weeks), which may have the advantage of evaluating the anti-VEGF molecules at their time of maximum effectiveness as opposed to the cumulative effects of monthly dosing. Some have proposed that dosing every 2 weeks versus 4 weeks 
Baseline macular thickness

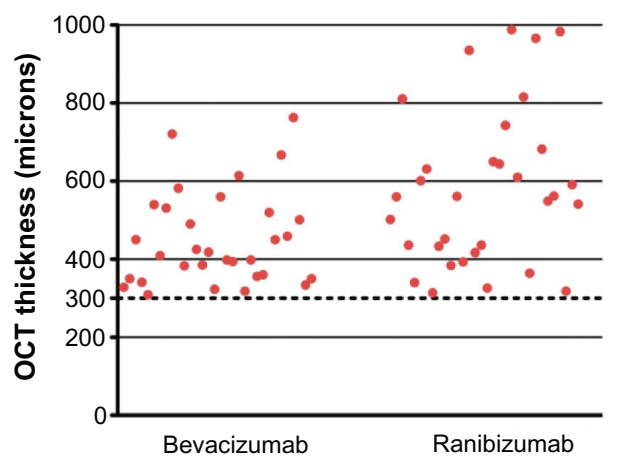

Macular thickness at 2 weeks

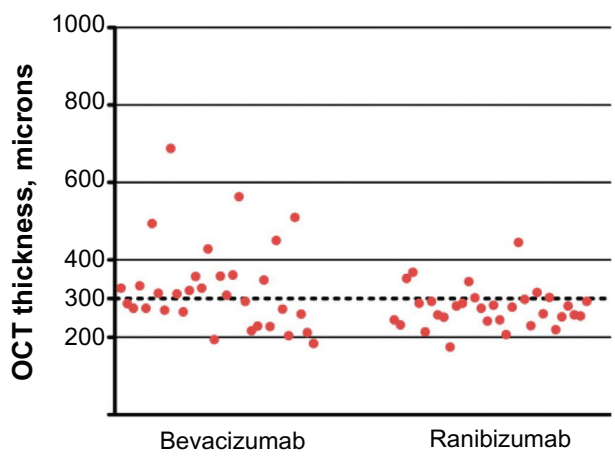

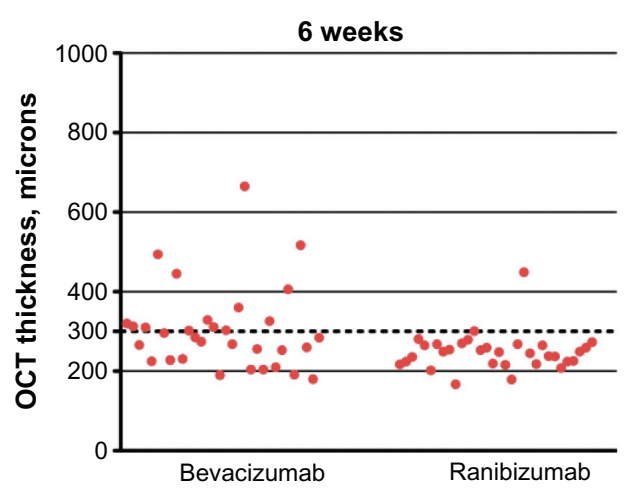

Figure 4 Scatter plots showing CMT of each patient at baseline, 2 weeks, and 6 weeks. Abbreviations: $\mathrm{OCT}$, optical coherence tomography; CMT, central macular thickness.

may be necessary for bevacizumab in cases with persistent or rebound macular edema due to overwhelming VEGF in the vitreous. ${ }^{15}$ This study allows us to compare these two agents at the 2-week interval.

In the BRAVO and CRUISE trials ${ }^{3,9}$, ranibizumab was able to decrease baseline retinal edema by a mean of more than $250 \mu \mathrm{m}$ as early as 7 days after treatment, (the earliest measured time point after injection per protocol) with even more effect at 1 month, continuing to 6 months. In addition, for CRVOs, ranibizumab was able to decrease excess foveal edema

Number of patients with macular thickness less than $\mathbf{3 0 0}$ microns

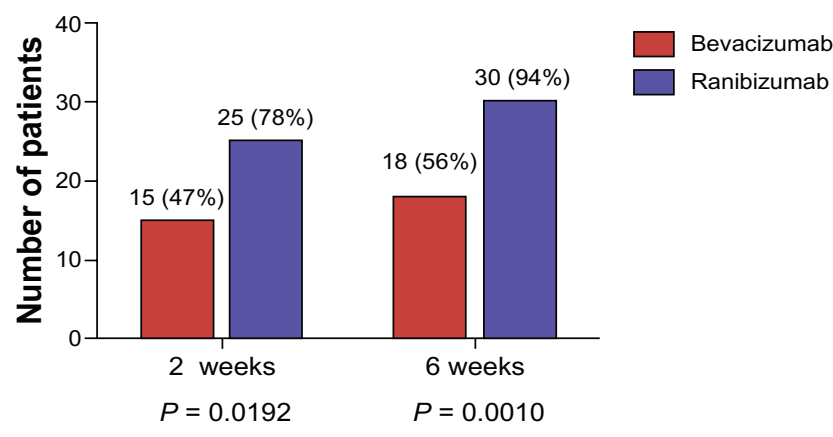

Figure 5 Total number of patients in each group with a CMT $<300 \mu \mathrm{m}$. Abbreviation: CMT, central macular thickness. from a mean of greater than $300 \mu \mathrm{m}$ at baseline, to approximately $100 \mu \mathrm{m}$ at 1 month. In the BRAVO trial, ranibizumab decreased excess foveal edema from a mean of almost $280 \mu \mathrm{m}$ at baseline, to approximately $150 \mu \mathrm{m}$ at $1 \mathrm{week}$, and less than $100 \mu \mathrm{m}$ at 6 months. ${ }^{3,9}$ This data is based on Stratus OCT with an assumed mean foveal thickness of $212 \mu \mathrm{m} .{ }^{16}$ In clinical practice, the physician wants to know "is the macula dry?" The closest numerical surrogate to this is central field thickness measurement. In Stratus, this is commonly considered $250 \mu \mathrm{m}$ (which is two standard deviations from the mean), and $300 \mu \mathrm{m}$ in Cirrus. For the purposes of this study in looking at CMT, $300 \mu \mathrm{m}$ was used as a cut-off for resolving macular edema. The percentage of patients who reached CMT $<300 \mu \mathrm{m}$, was $56.3 \%$ in the bevacizumab group versus $93.8 \%$ in the ranibizumab group at the 6 week interval ( 4 weeks post Ozurdex ${ }^{\circledR}$ ). This difference in the number of patients who reached CMT $<300 \mu \mathrm{m}$ between the two groups was statistically significant at both the 2 week and 6 week interval. In addition, when looking at overall percent change in CMT, ranibizumab had a statistically significant $(P<0.0001)$ greater reduction in CMT at the 2 week and 6 week intervals when compared to bevacizumab. Despite the fact that the ranibizumab group started with a higher overall baseline CMT, more patients in the ranibizumab group ( $93.8 \%$ versus $56.3 \%$ ) achieved a 


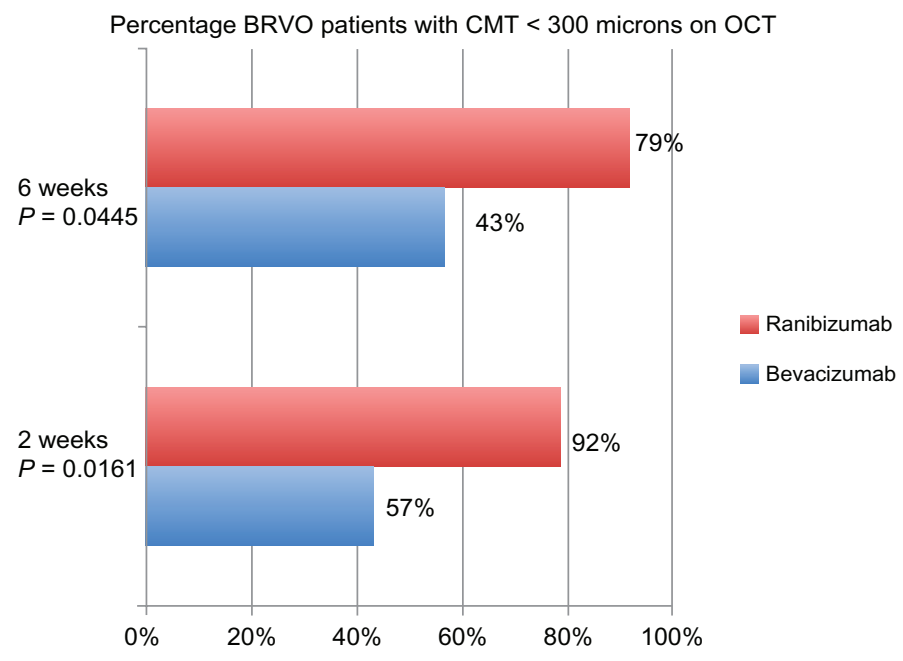

Figure 6 Percentage of BRVO patients with CMT less than $300 \mu \mathrm{m}$ at 2 and 6 weeks.

Abbreviations: BRVO, branch retinal vein occlusion; CMT, central macular thickness, OCT, optical coherence tomography.

$\mathrm{CMT}<300 \mu \mathrm{m}$. In terms of VA, there was no statistically significant difference between the two groups at baseline and each of the intervals. However, both bevacizumab and ranibizumab showed a statistically significant improvement in CMT and logMAR VA. It is interesting to note that despite the significant difference in CMT reduction between the two treatment groups, the VA was not significantly different at any of the intervals. This may be due to other variables not examined in this study such as duration of edema, degree of ischemia, or anterior segment opacities. Given that Snellen VA has less variation in possible data points when compared to OCT thickness measurements, a larger study with more patients may be more appropriately powered to find differences in VA. In addition, this study was designed to mimic clinical practice using Snellen as opposed to Early Treatment Diabetic

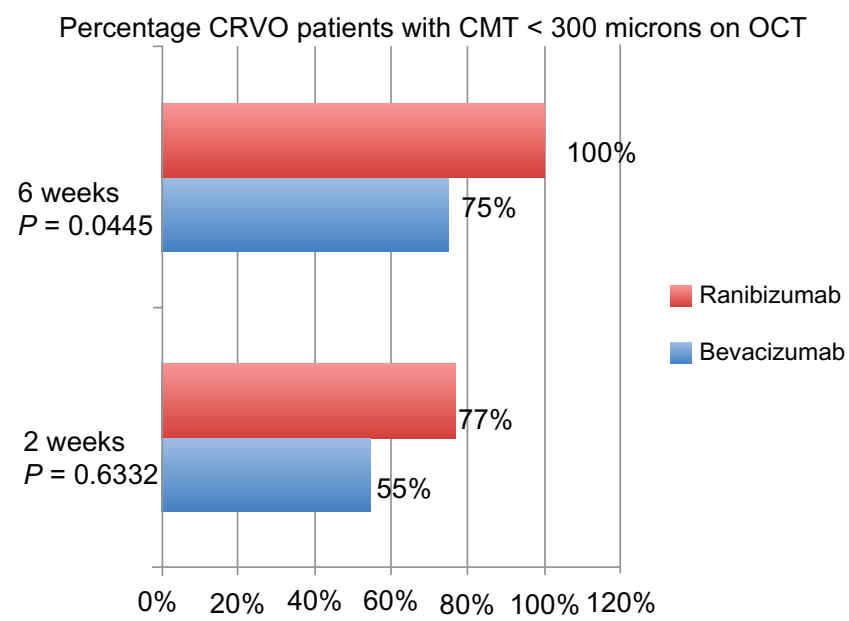

Figure 7 Percentage of CRVO patients with CMT less than $300 \mu \mathrm{m}$ at 2 and 6 weeks.

Abbreviations: CMT, central macular thickness; CRVO, central retinal vein occlusion; OCT, optical coherence tomography.
Retinopathy Study (ETDRS) refractions and patients were not "pushed" to see as many letters as possible.

The differences in reduction of CMT when comparing the patients with CRVO versus BRVO further supports the thought that ranibizumab may be more effective in treating macular edema in disease processes with higher VEGF levels. At 2 weeks, in the patients with CRVO, there was a statistically significant difference between the two groups in terms of percentage reduction of edema but not in number of patients with OCT CMT $<300 \mu \mathrm{m}$. However, at 6 weeks, all 8 patients with CRVO in the ranibizumab group had a CMT $<300 \mu \mathrm{m}$ versus 6/11 patients who received bevacizumab. This may indicate that over time, bevacizumab may not provide as much of a sustained effect in the presence of higher VEGF levels. However, additional studies with larger numbers would be needed to better evaluate these effects.

As research in this area continues to grow, and more medications are developed for treating macular edema, it will become increasingly necessary to tailor treatments to the specific disease process and patient. Applying appropriate agents, alone or in combination, based on levels of chemical mediators involved in the pathogenesis of macular edema will allow us to achieve the best possible results for our patients.

Table 3 OCT analyses of previously treated patients with bevacizumab

\begin{tabular}{lll}
\hline $\begin{array}{l}\text { Type } \\
\text { of RVO }\end{array}$ & $\begin{array}{l}\text { Number of patients }<\mathbf{3 0 0} \\
\text { microns at } \mathbf{2} \text { weeks }\end{array}$ & $\begin{array}{l}\text { Number of patients }>\mathbf{3 0 0} \\
\text { microns at } \mathbf{2} \text { weeks }\end{array}$ \\
\hline CRVO & $\mathrm{I}$ & 2 \\
BRVO & 6 & 5 \\
Total & 7 & 7 \\
\hline
\end{tabular}

Abbreviations: BRVO, branch retinal vein occlusion; CRVO, central retinal vein occlusion; OCT, optical coherence tomography; RVO, retinal vein occlusion. 
There are some limitations to this study including its retrospective nature, smaller sample size, and the fact that it was carried out at a single center. In addition, patients were not randomized, as the agent injected was mostly determined by insurance coverage. This can lead to some confounding variables that may not be taken into account in this study. One other confounder was that all patients received an Ozurdex ${ }^{\mathbb{R}}$ implant at the 2 week visit, which may make the 6 week data more difficult to interpret in terms of comparing bevacizumab and ranibizumab. However, this would not affect the 2 week data. In addition, it is interesting to note that even with the combination therapy, the differences noted for the CMT persisted 4 weeks after the dexamethasone implant. Another limitation is that some of the patients in the bevacizumab group were previously treated (Table 1 and Table 3). However, less than half of the bevacizumab patients were pretreated (14 of 32), and of those, $50 \%$ achieved a CMT $<300 \mu \mathrm{m}$. This percentage is actually slightly higher than the overall percentage of all of the bevacizumab patients that achieved a CMT $<300 \mu \mathrm{m}(47 \%)$.

Despite these limitations, we must take into consideration the fact that bevacizumab and ranibizumab are different molecules, and their differences may only become apparent in disease processes with higher levels of VEGF. Based on our study, in RVOs ranibizumab may have a more effective role in reducing CMT when compared to bevacizumab. Further study is needed to clarify longer-term data, and to provide comparison in a prospective, randomized manner. The CRAVE trial $^{17}$ (bevacizumab versus ranibizumab in treatment of macular edema from vein occlusion) is currently being carried out at other centers with a larger number of patients and will hopefully further answer this question.

\section{Disclosure}

MA Singer is a consultant for Genentech, Allergan, Regeneron, Acucela, Santen, and Thrombogenics, and receives research support from Optos, Neovista, Eyegate, Ohr. The other authors report no conflicts of interest in this work.

\section{References}

1. Klein R, Moss SE, Meuer SM, Klein BE. The 15-year cumulative incidence of retinal vein occlusion. The Beaver Dam eye study. Arch Ophthalmol. 2008;126:513-518.

Clinical Ophthalmology

\section{Publish your work in this journal}

Clinical Ophthalmology is an international, peer-reviewed journal covering all subspecialties within ophthalmology. Key topics include: Optometry; Visual science; Pharmacology and drug therapy in eye diseases; Basic Sciences; Primary and Secondary eye care; Patient Safety and Quality of Care Improvements. This journal is indexed on Submit your manuscript here: http://www.dovepress.com/clinical-ophthalmology-journal
2. US Census Bureau. Annual Estimates of the population by sex and fiveyear age groups for the United States: April 1, 2000 to July 1, 2007. NC-EST2007-01. Release Date: May 1, 2008. Available at: https://www. census.gov/prod/2008pubs/p70-117.pdf. Accessed February 16, 2010.

3. Campochiaro PA, Heier JS, Feiner L, et al. Ranibizumab for macular edema following branch retinal vein occlusion: six-month primary end point results of a phase III study. Ophthalmology. 2010;117: 1102-1112.

4. [no authors listed]. Argon laser photocoagulation for macular edema in branch vein occlusion. Branch Vein Occlusion Study Group. Am J Ophthalmol. 1984;98:271-282.

5. [no authors listed]. Evaluation of grid pattern photocoagulation for macular edema in central vein occlusion. The Central Vein Occlusion Study Group M report. Ophthalmology. 1995;102:1425-1433.

6. Noma H, Funatsu H, Yamasaki M, et al. Pathogenesis of macular edema with branch retinal vein occlusion and intraocular levels of vascular endothelial growth factor and interleukin-6. Am J Ophthalmol. 2005;140:256-261.

7. Noma H, Funatsu H, Mimura T, et al. Aqueous humor levels of vasoactive molecules correlate with vitreous levels and macular edema in central retinal vein occlusion. Eur J Ophthalmol. 2010;20:402-409.

8. Campochiaro PA, Hafiz G, Shah SM, et al. Ranibizumab for macular edema due to retinal vein occlusions: implication of VEGF as a critical stimulator. Mol Ther. 2008;16:791-799.

9. Brown DM, Campochiaro PA, Singh RP, et al. Ranibizumab for macular edema following central retinal vein occlusion: six-month primary end point results of a phase III study. Ophthalmology. 2010;117: 1124-1133.

10. Yilmaz T, Cordero-Coma M. Use of bevacizumab for macular edema secondary to branch retinal vein occlusion: a systematic review. Graefes Arch Clin Exp Ophthalmol. 2012;250:787-793.

11. Comparison of Age-related Macular Degeneration Treatments Trials (CATT) Research Group. Ranibizumab and bevacizumab for treatment of neovascular age-related macular degeneration: two-year results. Ophthalmology. 2012;119:1388-1398.

12. Labriola LT, Sadda SR. Rapid resolution of macular edema associated with central retinal vein occlusion using ranibizumab after failure with multiple bevacizumab injections. Semin Ophthalmol. 2011;26: 387-391.

13. Singer MA, Bell DJ, Woods P, et al. Effect of combination therapy with bevacizumab and dexamethasone intravitreal implant in patients with retinal vein occlusion. Retina. 2012;32:1289-1294.

14. Pieramici DJ, Rabena MD. Anti-VEGF therapy: comparison of current and future agents. Eye (Lond). 2008;22:1330-1336.

15. Stewart MW, Rosenfeld PJ, Penha FM, et al. Pharmacokinetic rationale for dosing every 2 weeks versus 4 weeks with intravitreal ranibizumab, bevacizumab, and aflibercept (vascular endothelial growth factor Trap-eye). Retina. 2012;32:4344-4357.

16. Chan A, Duker JS, Ko TH, et al. Normal macular thickness measurements in healthy eyes using Stratus optical coherence tomography. Arch Ophthalmol. 2006;124:193-198.

17. Barnes Retina Institute. Bevacizumab Versus Ranibizumab in Treatment of Macular Edema From Vein Occlusion (CRAVE). In: ClinicalTrials. gov [website on the Internet]. Bethesda, MD: US National Library of Medicine; 2011 [updated February 9, 2012]. Available from: http:// clinicaltrials.gov/ct2/show/NCT01428388. Accessed May 20, 2013.

18. Singer MA, Bell DJ, Porbandarwalla S. Ischemia and VEGF in different retinal diseases and therapies: how does one influence the other? Retinal Physician. 2012;9:28-30.

\section{Dovepress}

PubMed Central and CAS, and is the official journal of The Society of Clinical Ophthalmology (SCO). The manuscript management system is completely online and includes a very quick and fair peer-review system, which is all easy to use. Visit http://www.dovepress.com/ testimonials.php to read real quotes from published authors. 